\title{
Changing Social Focussing in the Development of Jazz Music
}

\author{
James Hay ${ }^{1}$, J David Flynn² \\ ${ }^{1}$ Western University \\ ${ }^{2}$ King's University College
}

This paper traces the development of jazz musical styles by relating those styles to the organization of jazz musicians and the social context of American society. The authors use a theory developed by Flynn and Hay (2012) derived from chaos and complexity science. The Flynn/Hay theory states that social focussing (chaos, complexity or order: SF) is directly proportional to internal structure (differentiation: D) and inversely related to external information (centrality: $C$ ). In mathematical terms: $S F=D / C$. The authors of this paper describe the social focussing of jazz styles in terms of being chaotic, complex or ordered. They then relate the styles of social focussing to the differentiation of the social system of jazz musicians, and the centrality inputs from the surrounding American society. Their results demonstrating that the style of jazz at each period from the late 19th century to the present era, is dependent upon the ratio of $d / c$. They conclude that the same analysis could be applied to subsystems of the jazz system, including the development of jazz styles in different geographic regions, as well as within each band and even over the career of each musician, in a kind of fractal effect, where the shape of social focussing is the same at each level.

url:

\section{Introduction}

In this paper we will examine the growth and development of the art form, jazz music. We will do this using the differentiation centrality/ (d/c) ratio developed by Flynn and Hay in their book (2012). Jazz is a musical art form that has evolved in the last one hundred years. Except for the very early days, that evolution has been recorded so that we can listen to the actual music, and this allows a unique musical perspective on its history.

The evolving complexity of jazz is a good illustration of what we might call post-modern or thirdorder cybernetics. Felix Geyer, in his extensive review of the history of the effect of cybernetics on sociology (1994), identified first-order cybernetics as consisting of morphostatic processes using negative feedback to maintain order. He described second-order cybernetics as morphogenesis, using mainly positive feedback processes which lead to change (Geyer 1995:9ff). Extending his ideas we see third-order cybernetics as fundamental transformations of the entire system. As we shall show, each stage in the development of the jazz system of musicians and producers, as well as in the music itself, is dramatically different in form and structure from the preceding stage. In the conclusion of this paper, we will elaborate on what we mean by third-order cybernetics. 
Much of the information and data used in our paper comes from Ken Burns' History of Jazz, the television programme and the accompanying book (Ward and Burns 2000; Burns 2001). The CDs issued with this programme illustrate the changing nature of the music, as discussed in this paper.

Although there is some blurring at the edges of the jazz world in its interplay with classical music and with the beginning of rock and roll, jazz is well defined by the music. The social system that we will explore consists primarily of the musicians playing this music, together with those directly involved with them such as record producers and concert promoters. Historically there has been an association with geography, from its origin in New Orleans, then its expansion north to Chicago, Kansas City, New York, and Los Angeles, and finally to its present world wide distribution, and we will refer also to this geographic migration.

\section{Social Focussing and the Centrality/Differentiation (D/C) Theory}

\section{The four states of social focussing}

We begin with a discussion of the term social focussing. The term refers to the behaviour of a social system, and can range from sheer chaos to extreme order. The term is closely related to Wolfram's study of computer-generated systems and their behaviour over time (Wolfram, 2002). In their recent book, Flynn and Hay developed a relationship which they named the $\mathrm{d} / \mathrm{c}$ ratio to explain why social systems move from one type of social focussing to another.

Stephen Wolfram used a variety of virtual systems, that is, computer models to demonstrated that almost all systems could be grouped into what he called four classes. The four classes are chaos, complexity and two kinds of order: repetitive and fixed. Wolfram studied literally millions of virtual systems, beginning with cellular automata (CAs). To illustrate his findings, we will use his results for simple CAs.

CAs consist of an initial row of cells which change colour based on certain Boolean rules e.g. if, for a given cell, one of the adjoining cells is white, the cell becomes white at the next step; if both adjoining cells are black, the given cell become black. No matter how complicated these virtual systems - two or many dimensions, very complicated connections - the resulting pattern after many steps almost always fell into one of the four classes (Wolfram, 2002: 51ff; for an earlier use of CAs to produce the four classes see Varela et al., 1993; Geyer 1995:15).

The chaotic class has no obvious pattern, changing over time in unpredictable and undefinable ways. Furthermore, chaos is very sensitive to changes in the initial conditions - the original arrangement of cells (see Figure 1). 


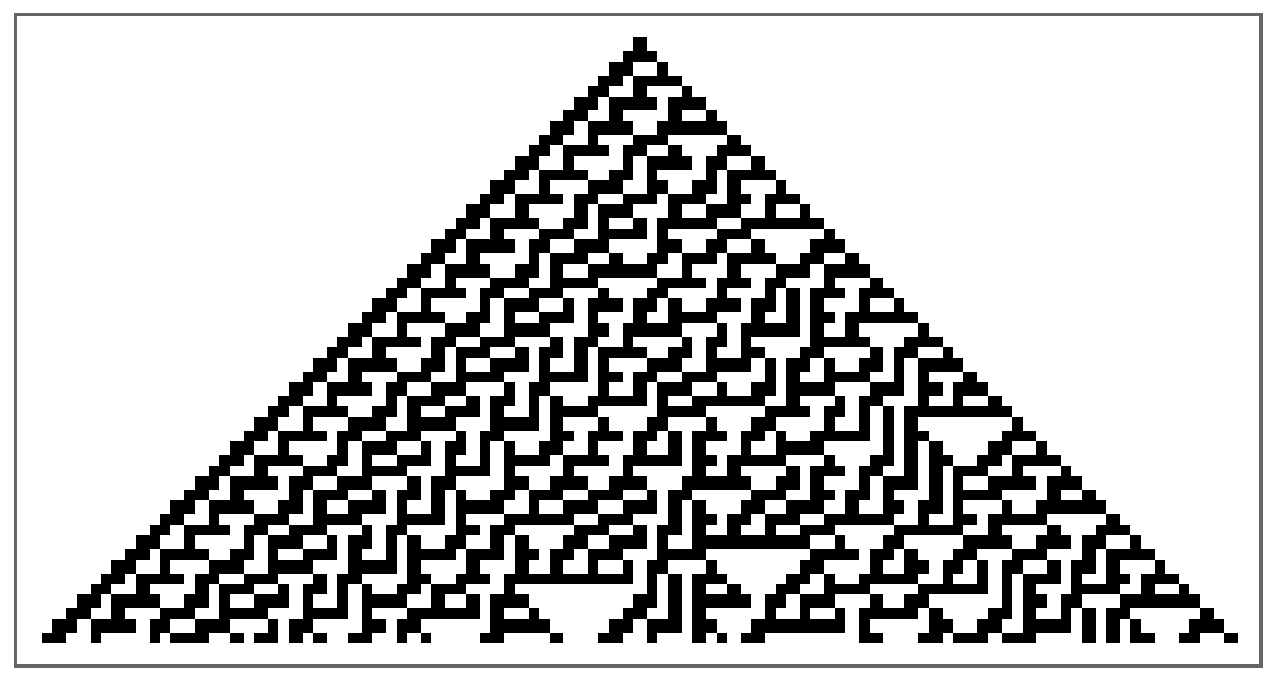

Figure 1. Chaotic Class 1

The second class, complexity, is a mixture of chaos with some constant ordered patterns. New initial conditions tend to cause only local changes if made in the ordered patterns but the system will be very sensitive to changes in initial conditions when those changes are made in the chaotic part of the system (see Figure 2).

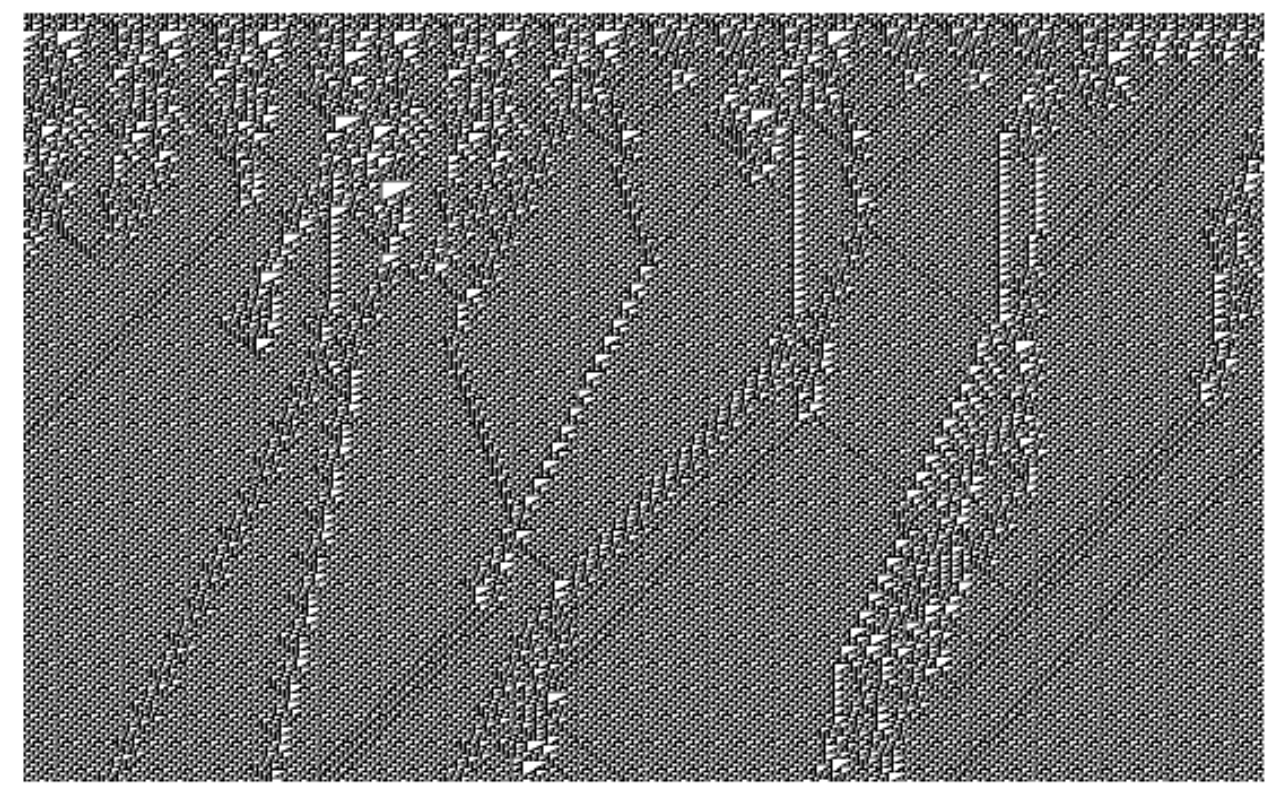

Figure 2. Complex Class 2

The class of repetitive order is a pattern which repeats over and over, no matter what changes are made in initial conditions (see Figure 3). 


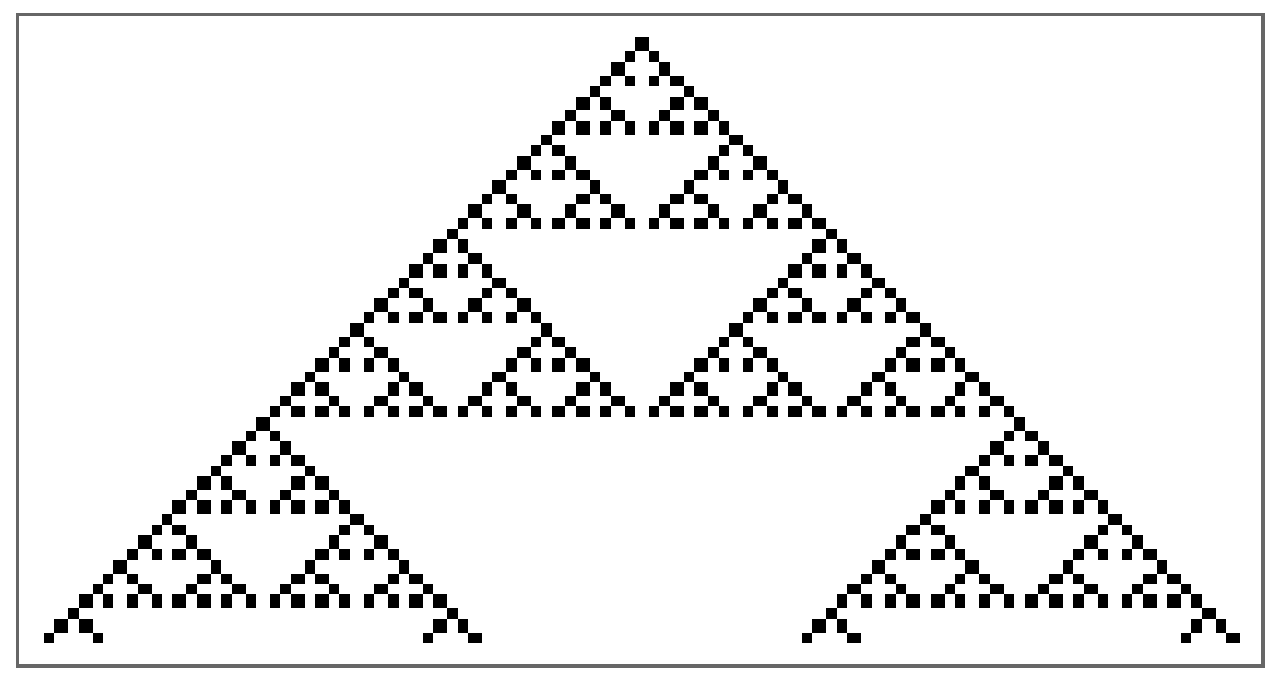

Figure 3. Repetetive Order Class 3

The fourth class, Fixed Order, results in a pattern which never changes no matter what changes are made in initial conditions (see Figure 4).

Figure 4. Fixed Order Class 4

Wolfram's experiments were done with many kinds of discrete systems in addition to simple CAs. By discrete, Wolfram meant that the systems are made up of entities which change in a stepwise process, that is, they are not continuous systems. Since social systems are also discrete, made up of individual human beings who change step by step as a result of their interaction with each other, they are also discrete systems. Hence, Flynn and Hay concluded that social systems must also exist mainly in one of the four Wolfram classes (2012: 20). To make it clear that we are dealing with social systems, where the term class has a very different meaning, we will use the word state instead of Wolfram's term class to describe the behaviours of systems generated by social interaction over time. Specifically, we will use Flynn and Hay's terms of social focussing to refer to each of the four forms of social behaviour. (For additional discussion of applying results from computer models to social systems, see Geyer 1995:12, 16-17).

Flynn and Hay (2012) introduced the concept of social focussing to describe the behaviour of social systems in the four states. Social focussing is analogous to the light from a flashlight which can vary from almost random flashes - chaotically focussed - to a fixed focussed beam. 
Chaotically focussed systems are like a flashlight which moves around in unpredictable ways. The slightest disturbance moves the light to a different spot. It seems impossible to detect any pattern over time so that descriptions of what transpires become as detailed as the events themselves. We see chaotic focussing when we observe a crowd in a shopping mall milling about.

Ordered focussed social systems, at the other end of the focussing scale, do behave in predictable ways. Repetitively ordered focussed systems resemble a flashlight which goes on and off in a steady way which can be summarized in a short formula. Most social organizations are repetitively focussed, repeating the same basic procedures over time as described in manuals of regulations and instructions.

Fixed ordered focussed social systems are like a flashlight burning brightly in one direction no matter what happens. Extreme social movements, popularly called cults, tend to be fixed ordered focussed, as they repeat rituals, almost impervious to the influence of outside forces.

Between chaos and order are complex focussed systems. Such systems have some constant patterns of behaviour, but also have other patterns which change in unpredictable ways depending upon external influences. The pattern would resemble a flashlight attached to a football in a dark field. Most of the resulting light patterns would be chaotic, but there would be some more ordered patterns related to the rules of the game. Through evolutionary processes, biological systems tend to behave in complex ways. Such systems can resist changing in response to sporadic external threats while able to adapt to more permanent changes in the environment.

Now, the question of great interest to social scientists: why do social system change their social focussing behaviour? In particular, for this paper, why did the system of jazz change at various points in time, becoming chaotic, ordered, or complex?

\section{The $d / c$ ratio as a cause of changes in social focussing}

For Wolfram's CA systems, what determined which of the four classes was produced, was the initial conditions and the Boolean rule that determined the appearance of the next row. For a given initial condition, each rule generated one, and only one of the four classes.

Social relationships are controlled by many more rules than even the most complicated virtual systems modelled by Wolfram. Wolfram and others have discovered that it is essentially impossible to predict the class of even the simplest CA without actually running the system, so it is obviously impossible to predict the state of even a very simple social group, using only the knowledge of initial conditions and the rules of interaction. As well, social systems are more open to external influences than a computer model so that there are many factors which affect the initial conditions at any one time, and, hence, the behaviour state of a system.

Flynn and Hay developed another approach to predicting the state of social systems' focussing. They define this approach as the ratio of two social science variables, differentiation divided by centrality: $d / c$ (2012: 31ff). Differentiation refers to the internal structure of the system and corresponds to the rules in a $\mathrm{CA}$, although much more complicated.

Centrality is the input of new information coming from outside the system. For a CA, this corresponds to the initial conditions at any one time.

Flynn and Hay discussed several ways of measuring differentiation and centrality. They broke down the variable of differentiation into four parameters described by Scott Page (2009). The four Page parameters are diversity, connectedness, interdependence and adaptability (Flynn and Hay, 2012: 
32-41). In brief, differentiation is measured by the variety of subsystems, as well as the manner in which those subsystems are organized, that is, connected, along with mutual interdependence and the ability of subsystems to adapt to change. In this paper we will measure differentiation with only the first two parameters, diversity of and connectedness among the subsystems.

Centrality, the variety of outside information entering the system, also can be measured in many ways (Faust and Wasserman, 1992) but a crude way to measure centrality is to observe the external links to other systems, and that is the indicator we will use in this paper.

Flynn and Hay then used Ashby's Law of Requisite Variety (Ashby, 1966 (1956) Geyer, 1995: 27), and Young's discussion of community solidarity (Young and Young, 1973) to argue that social focussing is related to the ratio of differentiation to centrality (2012: 66ff). That is, the higher the level of centrality - more incoming information - the more chaotic is the system, since the new information tends to disrupt the system's focussing. Higher centrality lowers $\mathrm{d} / \mathrm{c}$, if differentiation remains constant, hence, the system is less focussed (Hay and Flynn, 2011).

On the other hand, more ordered focussing is the result of increased differentiation. So we would expect more order with more diverse subsystems, the first Page parameter (Hay and Flynn, 2011). However, these diverse subsystems must be highly interdependence and adaptable, the final two Page parameters (Flynn and Hay, 2012: 31ff). With higher differentiation, based on these three characteristics, the more able is the system to cope with outside information (centrality). As long as centrality is constant, higher differentiation raises the $\mathrm{d} / \mathrm{c}$ ratio, and produces more ordered focussing.

In their book, Flynn and Hay were unable to find a similar proportional relationship between the second Page indicator of differentiation, connectedness, and social focussing (2012: 34-35). One cannot say that order is related directly to the number of connections among subsystems. Rather, it is the way in which they are connected into various types of networks which affects focussing.

Hay and Flynn recently published a paper on networks that used computer models to examines several kinds of networks to see how they affected focussing (2015). They compared networks based on random connections to the other extreme, a hierarchy. They discovered that each network does seem related to a type of focussing. For randomly connected networks, chaos increased as the number of connections increased, which implies that differentiation is lowered. On the other hand, hierarchical networks were more ordered - the result of higher differentiation. In between, complex focussing came from what Watts called small world networks - clusters of highly connected subsystems weakly connected to other clusters (Watts, 1999; See also Geyer 1995: 19, 24).

In general, then, when the $\mathrm{d} / \mathrm{c}$ ratio is very low, that is, differentiation is much less than centrality, the system will tend toward chaos. At the other extreme, when the ratio is quite highdifferentiation is much greater than centrality - the social system will more likely be in one of the two ordered states.

Around the point where the two variables of differentiation and centrality are approximately matched, systems will be in the complex state, a mixture of chaos and order, which early complexity scientists called the edge of chaos. It is in this complex state that new order emerges. Although Kauffman and others have tried to analyse the phenomenon of emergence, the appearance of "order out of chaos," the phenomenon remains somewhat mysterious (Corning, 2002; Geyer, 1995: 22-23; Holland, 1998; Kauffman, 1995:23-24). In terms of d/c, it seems that when differentiation and centrality are just matched, the resulting behaviour is somewhat unstable (although not chaotic) so that small changes in centrality may trigger new combinations of existing 
order, or even new differentiation. Out of this instability arise new forms of order as we will discover later when we discuss the emergence of new styles of jazz.

Undoubtedly there are many other factors affecting the focussing of social systems, but the $\mathrm{d} / \mathrm{c}$ ratio appears to represent an underlying causal relationship which we will use to study changes in jazz music.

\section{The Social Focussing of Jazz Music}

The focussing of jazz music itself is easier to classify than the focussing of the behaviour of jazz musicians. Yet the music must reflect to some extent the focussing of the social system of musicians, along with those who promoted and distribute it. The focussing of the music is more obvious because it involves easily distinguishable styles. We analyse these styles through the musical approaches and the theoretical bases of the music, and differing styles can be easily recognized by the listener

We will be relating the changes in this music to changes in centrality and differentiation of the social system of jazz. Since the change in centrality refers to changes in the variety of incoming information, centrality for the musical system of jazz includes new musical ideas and theories from external musical influences such as classical music and rock and roll. But it also includes social and political information and, particularly, changes in race relations as they impact this group of musicians.

Differentiation also changes within this social system. It includes the diversity of different types of instruments and, indeed, the development of variations in each instrument and new ways of playing. It also includes changes in the makeup of the musical unit from piano soloists, to small groups, to large bands. As well, there were changes in chord progressions and structure, and the rhythms. An ongoing effect on differentiation was the number of musicians with formal musical education.

Differentiation, and, hence, social focussing, is also related to the network structure of the band, ranging from loosely, almost randomly connected musicians improvising freely, to the more rigid hierarchy of big bans led by strong leaders. Within the wider social system of jazz, differentiation also changed with the increased power of record companies and promoters. The musical networks were also affected by different venues and, later, being played on radio and TV. All these changes in network connections affected the social focussing of jazz.

So, depending upon the external centrality, changes in differentiation would have changed $\mathrm{d} / \mathrm{c}$ and move the system between order and chaos.

Figure 5 is an overview of how changes in $\mathrm{d} / \mathrm{c}$ affected the social focussing of the music, as identified by the names of varying styles over the history of jazz. 


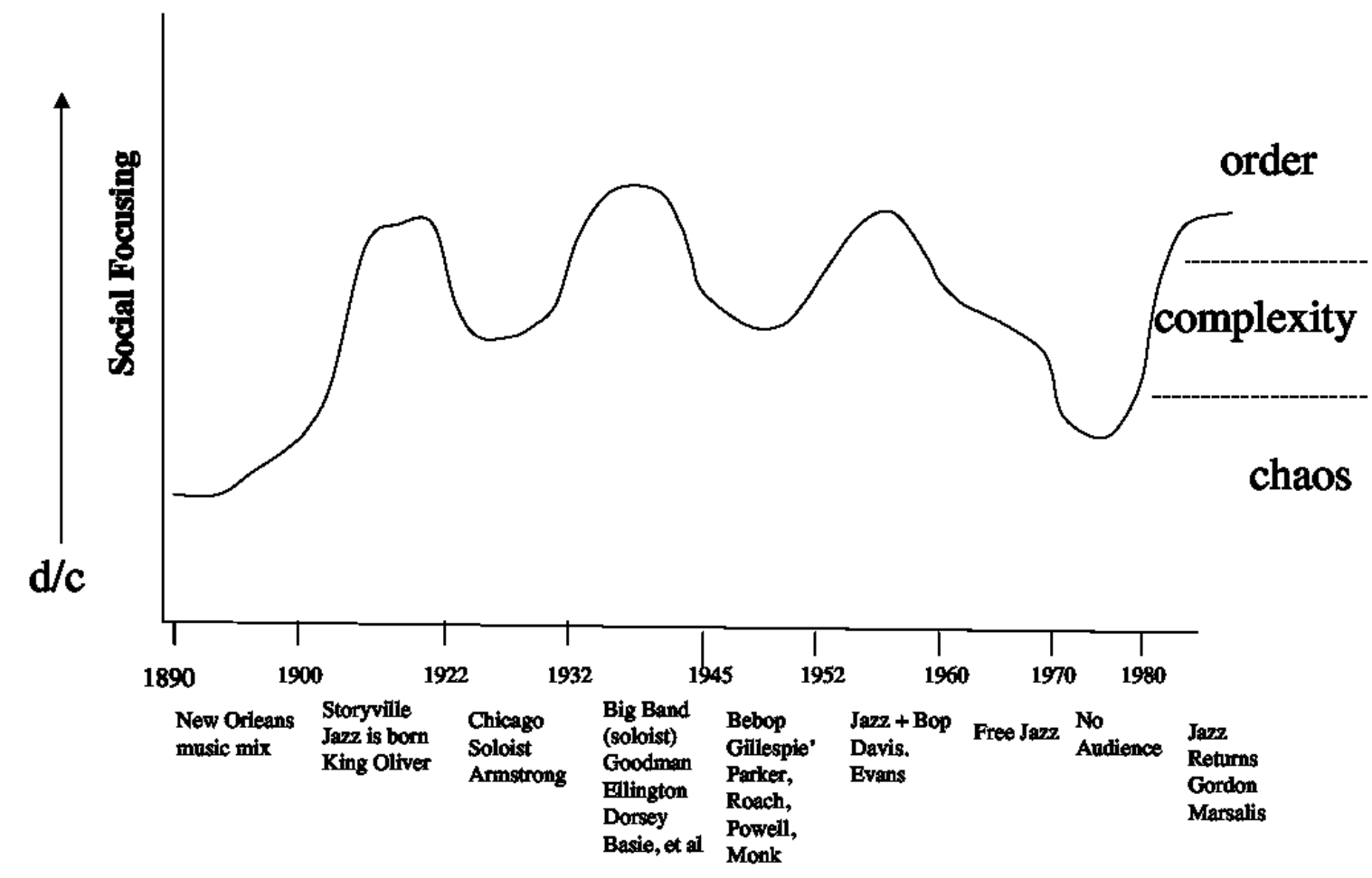

Figure 5. The changes in social focussing $(d / c)$ and jazz style over time

Jazz was unlikely to have developed outside America. It emerged from the interaction of many musical cultures from the time of its origin in New Orleans. It was stereotypically American where individuals have the freedom to create their artistic expression while at the same time they 'negotiate' their musical relationship with other musicians.

The history of jazz is especially related to the American history of black and white relationships. While some major figures in jazz come from the white race, it is very clear that the seminal creators were mostly black. Against the background of heart-breaking racism these people persisted. A sensitive white musician once said to Dizzy Gillespie, "I feel like I am stealing your music". Dizzy's classic reply was "You can't steal a gift".

\section{The musical environment in New Orleans in the 19th century: Chaotic focussing}

New Orleans founded in 1718, was ruled by France, Spain, and, finally, the United States. The city had French and Spanish-speaking settlers, including French-speaking ones from Canada and Haiti, and Spanish-speaking immigrants from Santo Domingo. Later, it had newcomers from the Balkans, Germany, Ireland, Italy and, indeed, most countries of Europe. In 1860, 40\% of the population was foreign-born. It was also a major slave-trading centre and blacks, both free and slaves, were a major part of everyday life. All these people brought their own music with them.

Eventually, three classes arose in New Orleans: white, Creole (people of lighter colour), and black. At first, the music of each was accessible the others, and the walls between these groups were quite permeable.

In the latter part of the 19th century, band music was popular throughout the US In New Orleans, there were French, Spanish, Irish, , and Italian marching bands. After the Civil War there were regimental bands, both black and white. New Orleans also had funeral parades with marching bands that played dirges out to the cemetery, and celebratory songs on their return. The sound of band music could be heard everywhere. 
The city also boasted three opera houses and two symphonies, one of which was Creole. Many Creole musicians were classically trained (some in Europe) and this was of major importance in the development of jazz.

Thus, musicians in New Orleans in this early period had access to a broad range of music, including African, Caribbean, European, American, classical and contemporary popular music. This popular music included the recently emerging ragtime that had begun in the black communities of Midwest America but soon arrived in New Orleans.

In addition, blacks moving into the city brought with them the work songs, the blues and the gospel music of their Baptist Church. It was in this dynamic musical environment and, in particular, from ragtime, blues and gospel, that jazz was born.

With a multiplicity of traditions coming into New Orleans the centrality for local musicians was very high, but in these early years, there was not sufficient differentiation to cope with the high centrality. Diversity was too limited to incorporate the wide range of incoming musical styles and ideas. Furthermore, the musical system was made up of a large number of relatively small nodes, loosely connected, almost randomly to one another. This type of random network typically produces chaotically focussed behaviour (Hay and Flynn, 2015:297-298).

Thus, with higher centrality and constant differentiation, the overall musical environment was chaotically focussed. That is to say, there were many kinds of music and each was easily influenced by other styles; each had a sensitivity to initial conditions - it was a chaotic scene.

\section{The creation of jazz, a new musical genre 1890-1900: Complex focussing}

In the post-civil war period of the 1890s, 'Jim Crow' laws were imposed on New Orleans. A drop of black blood determined that a person was black and must live in black neighbourhoods. The result was that black musicians had to perform in black venues, and Creole musicians had to work with black musicians in the marching bands and dance halls of black New Orleans. The overall centrality of New Orleans music declined, while differentiation rose (see below). The net effect was to raise the $\mathrm{d} / \mathrm{c}$ ratio, and move the social system from chaos into complexity.

At the end of the 19th century a style of music emerged from this complexity which extracted ideas from African rhythms to marches to European classical music, and it became organized into a new musical form. We think this happened primarily because centrality was reduced for the musicians playing in the black dance halls of Storyville, since their contacts outside this social milieu were limited.

At the same time, their musical skills were enhanced as the Creole musicians, some with classical training, were forced to play with them, thus increasing the differentiation of all these musicians. So, the $\mathrm{d} / \mathrm{c}$ ratio increased, and the system moved into complex focussing. It was this group of musicians in this state of complex focussing who developed the basic form of jazz: New Orleans style jazz.

The music system developed into a small world network of several tight groups in Storyville, within each of which there was much interaction: There were some weaker links among the groups as some musicians moved from group to group, but overall they were clusters, only weakly connected to other. The complex phase lasted only a brief time but from it emerged the great musical tradition of classical jazz.

New Orleans original jazz 19oo-1922: Repetitively ordered focussing 
A sign of increasing hierarchical order was the change from everyone playing the same music, to the appearance of an elite group of musicians who were the only ones to master this early form of jazz. At the same time, differentiation increased for this group at the top of the hierarchy as they developed a diversity of specialized skills, and as they assigned specific roles to individual instruments. Differentiation increased as musicians began playing in their own style.

The centrality of this group remained low as they were compelled to live in the relatively isolated black area. This low centrality and higher differentiation raised $\mathrm{d} / \mathrm{c}$ so that the musical social system moved out of complexity and became repetitively order focussed. New Orleans jazz, a distinctly new type of music, now had its own predictable musical structure.

This jazz was essentially an ensemble (polyphony) music played in syncopated 2/4 time by a small group of musicians consisting originally of drums and tuba as rhythm, and a 'front line' of coronet, clarinet, and trombone. All musicians took 2 or 4 bar breaks and, occasionally, longer solos - the front line instruments usually playing the solos, with the rhythm group as background. In general, the coronet played the lead of the melody, the clarinet played in harmony above, and the trombone below the coronet. It incorporated call and response ideas from gospel and, within its structure, provided a wide latitude for improvisation on every instrument. Yet there was an underlying repetitive pattern already recognizable during this period of increased focussing.

The music was played for dancing and marching, and the rhythm and rhythm variations were as important as melody and melodic variations. As well, other instruments - piano, bass tuba, violins, banjo, and guitars - were incorporated into the bands, but the overall musical structure stayed the same.

Jelly Roll Morton, a Creole, was a jazz pianist. Beginning in 1905 he began developing the theory behind the music, composing new tunes and writing down known tunes of this new music. It was a sophisticated music and was already developed far beyond a folk art.

There were many famous musicians and bands_-black, Creole and white_-but the black bands in Storyville 'tonks' were playing the best of this music. The great clarinettist Sidney Bechet developed his talent here. The bands of Joe 'King' Oliver were reputed to be the best and he was the king of the coronet players. Most important to the future of this music was the talent of Louis Armstrong, developed in these early bands in New Orleans.

There were notable Creole bands, such as Freddie Keppart's Creole Orchestra, which toured the USA playing this music.

One of the early white bands was the Original Dixieland Jazz Band (first recorded in 1917). Soon there were many bands playing throughout America. This was the basis for the music of the jazz age. For many of the musicians outside New Orleans, this was a novel form of pop music and they played it until the public tired of it.

Thus we have a new musical structure called New Orleans style or Dixieland that was subject to numerous variations but retains its recognizable form even today.

\section{The development of soloists and orchestras 1923-1932: Complex focussing}

As this style spread beyond the borders of New Orleans in the 1920s, its centrality increased and the system moved back from order into complexity, becoming a small worlds network again, with many clusters interacting only weakly with other clusters. With the closing of Storyville in New Orleans in 1917 and with the increasing opportunity of better employment in the North, there was a 
large migration of Southern blacks to the northern USA after WW1, especially to Chicago. Here the centrality of the original New Orleans' musicians was increased as they were exposed to the freer northern environment, despite the fact that black neighborhoods were confined to South Chicago where there grew a community of bars and dance halls. Here the New Orleans' jazz musicians retained their core identity, but also developed new patterns, typical of a complex system.

At the same time as centrality rose, differentiation increased also, but not to the same extent. The increased diversity was mainly the result of the development of the soloist. It appears, however, that the impact of the new surroundings, while it stimulated greater differentiation, centrality still exceeded the diversity of this group of musicians, which meant that the $\mathrm{d} / \mathrm{c}$ ratio was lower than in New Orleans. The result was that the ordered focus of the original New Orleans jazz changed to a small worlds network of complex focussing.

The small world network now extended from New Orleans to Chicago, Kansas City and New York. Each location was a tightly connected cluster only weakly connected to each other, and, therefore, more complex. It was within this fomenting environment that the range, depth and theory of jazz evolved to a new musical type different from but growing out of New Orleans jazz.

For example, it was during this time period that the extended solo and the soloist's ability to create new long melodic lines was added. In addition, the creation of large orchestral jazz, featuring brass and reed sections (often playing call and response) were developed. This included changing the time signature to $4 / 4$ (played with accent on 2 and 4 and as straight 4/4) and the development of swing - which became the defining characteristic of later jazz.

A notable band that came to Chicago at this time was King Oliver in 1918. Louis Armstrong joined him in 1922, and it was here that the genius of Armstrong and many others developed. The preserved recordings of this music, particularly of Louis Armstrong's Hot 5's and Hot 7's, allow us to hear it.

This music defined swing. It also defined jazz as music to display the artistry of the soloist, who built new melodies and rhythms on the chord structure of the tune. Many young white musicians listened to this music and sat in when asked.

Duke Ellington, the great jazz composer and orchestra leader, began his career in Washington, and brought his band to New York during this period. Fletcher Henderson started his Big Band and played at the Roseland Ballroom in New York. Chick Webb was featured with his band at the Savoy Ballroom in Harlem. These and a number of other regional bands developed the structure of what became known as big band jazz in the later, more ordered period described in the next section.

These bands now contained a rhythm section of drums - a distinctive drum set style was developing - as well as a string bass, guitar and piano, along with brass and reed sections. The arrangements, both written and 'head' — meaning with no written music — featured the sections interacting in many ways and established a musical structure within which the soloist could play, improvising directly on the chord structure.

Out of all this complex experimentation, came the classical era of big bands and the great soloists of the 30 s and early 40 s.

\section{Big bands and great soloists 1932-1945: Repetitively ordered focussing}

The focussed output of this next classical period is the sound of swing. It was foot-tapping music, and by the 1930's it was well-developed. In the race relations and perceptions of the time it was 
often explained as a 'natural' music arising out of the black race and their innate sense of rhythm and melody. It was not - it was a highly developed musical structure requiring the ability to read music and develop original melody and rhythmic variations on the chords of the melody during the performance. The musician had to have knowledge of and the ability to play in essentially all keys and chords.

By the 1930s jazz was widely played and had become a very sophisticated music but it was also the popular music of the day, particularly among young people. It remains, probably, the most sophisticated and popular music of the 20th century.

It was played widely by a variety of musicians - at one time about 40,000 musicians were employed in the big bands. While the music was defined by rhythm - swing - and by its use of chord structures and harmonies, it contained ample room for innovation and creativity.

New musician brought in new ideas, increasing the centrality of jazz, with influences from around the world. Radio and TV brought jazz to a wider audience- by the end of the Thirties $70 \%$ of the income of the record companies came from swing musi-and, in turn, this raised jazz centrality through the influence of record and media producers.

Their differentiation increased even more markedly, however, as the number of trained musicians playing in a varied array of bands and small groups, some with soloists, grew even faster.

Differentiation also increased chord structure and harmony, this general structure contained ample room for innovation and creativity, but at its core was the repetitively ordered classical big band style.

There was a prolific output of new music in the American musical theatre and 'tin pan alley'. This gave an increased base of new music for the jazz player. Many of these songs became jazz 'standards'. The combined result of increased centrality, with an even greater rise in differentiation, produced a d/c ratio well above one, and, hence, resulted in a repetitively ordered focussed music. This was, indeed, the classical period of jazz as the music spread across North America and to Europe.

It was classical in many ways. Big band music, while leaving room for creativity, was repetitively defined. It was not like an orchestra and it was not like a marching band. There was a hierarchy of bands and musicians, forming a network of hubs, connected to the major hubs of top bands widely known throughout the world.

In 1933 Benny Goodman formed his first big band. He and other famous white musicians, such as Artie Shaw, had played with black musicians and listened to their music. These white bands led America into jazz music. During the Depression and WWII, Americans danced to the music of jazz. It was the major part of the pop music scene.

Radio played a key role, with late night remotes from across the country. Recordings of the music were everywhere and record executives such as John Hammond and, later, Norman Granz organized the presentation of this music. In addition to Goodman and Shaw there were many great bands with national reputations such as Glen Miller, Tommy Dorsey, Woody Herman, Charlie Barnet, Claude Thornhill, and, later, Harry James, Gene Krupa, Stan Kenton, and many others. There were innumerable local bands further down the hierarchy.

Again, because of racial discrimination, the black bands did not get the national attention and radio time at the start of this period. In fact, Fletcher Henderson disbanded and became Benny

Goodman's arranger. Soon, though, Ellington began broadcasting from the Cotton Club. The white 
bands started to include black musicians in the mid-Thirties. Ultimately, the great band of Count Basie joined Ellington as an established black band.

These bands featured the great jazz soloists who defined the many possibilities of the solo instrument, and, in many cases, established the style of playing their instrument for decades to come. Among these were Louis Armstrong, Roy Eldridge, and Cootie Williams on trumpet, Coleman Hawkins, Ben Webster, Lester Young, Johnny Hodges, and Harry Carney on saxophones. In addition, there were major drummers such as Joe Jones, Gene Krupa, Buddy Rich and Louis Bellson who established new ways of playing this recently developed drum kit.

In addition to the big bands, jazz was played in small groups, including groups within the big bands. Here the genius of these musicians was on display. Among the many great performances, Body and Soul, recorded by Coleman Hawkins in 1939, was a milestone and illustrated the artistry of the jazz soloist in a small group.

The classical structure of big band music and solo performances based on the chord structure of the melody was now firmly established in a repetitive kind of ordered focussing. The rhythm structure and its variations was now established. Great jazz pianists had appeared on the scene, as had the great jazz vocalists. Jazz was a global music, now played everywhere in the USA and in many other parts of the world, but particularly in Europe, where many jazz musicians moved.

This repetitive order came from a hierarchically structured network. At the base of the hierarchy were the musicians who were hired by the bandleaders. The powerful bandleaders chose the music (based on the talent of their musicians) and organized the business of their band-where they played and the recordings they produced. The bands and their fans were connected through a few very powerful record companies (Columbia, RCA Victor, Bluebird, Capitol, Decca) who chose the recordings that defined the music. As well, radio networks - CBS and NBC - presented live performances and played the records that brought the music to its mass market (Myers, 2013). Many musicians were connected to these major hubs that defined classical big band jazz. At no time, however, was this jazz social system controlled by a single hub or even a few hubs, so fixed order focussing never developed. As well, some musicians moved among the elite bands. Other musicians listened and used that knowledge to adapt the music to suit their fans, but the basic sound was a repeat of the style of the great bands at the top.

\section{The development of bebop 1940-1953: Complex focussing}

The centrality of musicians, particularly black jazz musicians, was increased as WWII impacted their lives, especially through service in the armed forces. This increased centrality forced the $\mathrm{d} / \mathrm{c}$ ratio down, and the jazz system moved from order into complexity. Out of this complexity, emerged bebop. It began with a small group of musicians in New York in the early Forties that expanded the theoretical musical limits of the classical jazz form.

Racism still continued, however, and musicians were often treated poorly as they travelled across the US, which contrasted with their treatment in Europe. Yet their talent was recognized and their artistic stature and income increased. Overall, then, this greatly increased their centrality and decreased the $\mathrm{d} / \mathrm{c}$ ratio, putting this group into complexity.

As we discussed in the first part of the paper, complexity consists of both order and chaos. New order may result from combinations of older patterns, or from new differentiation. In this case, bebop greatly increased the diversity of the established jazz music by introducing new chord structures, chord progressions, and different rhythms. To play this music required greatly increased 
musicianship on the instruments and new ways of playing. This increased differentiation occurred only among a relatively few musicians who were capable of playing this music.

The creators of bebop were a small group of New York musicians, including Dizzy Gillespie (trumpet), Charlie Parker (alto saxophone), Thelonius Monk and Bud Powell (piano), Kenny Clark and Max Roach (drums). All of these skilled musicians felt limited by classical jazz. They felt more confident with the extra centrality and they wanted to expand the jazz world. They did!

This music still swung (as they say in the jazz idiom) but it admitted large extensionsS. The rhythm played by the soloist was much more intricate, with accents played off the beat in many interesting ways. The drum, piano, and bass played a new polyrhythm structure. The music required instrumental skills, coupled with the ability to move around keys and chord structures and to create new rhythmic patterns.

This new jazz led to major arguments about its value but by the end of the Fifties it was being incorporated, at least in part, into much of jazz. Although the music swung and one could dance to it, the public no longer danced as they had in the 40s. Often the music was presented for careful listening in nightclubs and concert halls.

The music was designed for the creative soloist, and so ensemble playing decreased. Hence, network structure evolved into more and smaller hubs, many only weakly connected or even unconnected to the bigger clusters, again, a typical small worlds network of complexity.

In August, 1942 the musicians union challenged the record companies pay structures, and banned recording by union members until pay increased. Singers continued to record but big bands did not. The major studios held out until November, 1944 and by then the big band music had declined, to be replaced by singers such as Frank Sinatra, and, subsequently, by rock and roll.

The community of jazz fans also declined. Most of the big bands disappeared and most musicians left the jazz scene. The loss of these musicians greatly reduced differentiation, however, the development of bebop replaced this differentiation in the now much smaller jazz community. The centrality was greatly reduced as jazz was no longer pop music. The net result was a rise in $\mathrm{d} / \mathrm{c}$ as differentiation increased and centrality decreased, so that the jazz world returned to repetitive order as described below.

And jazz survived. Some of the great orchestras continued, particularly Duke Ellington and, except for two years, Count Basie. They played more concerts and fewer dances, and made records with more innovative music. In particular, Ellington composed longer works.

\section{Cool jazz merges bebop into classical Jazz 1952-1960: Repetitive Order}

Gradually bebop became more widespread and musicians adapted it into their jazz ideas. This increased differentiation and the $\mathrm{d} / \mathrm{c}$ ratio, resulting in the reestablishment of an overall order in the jazz world to form a new jazz style termed 'cool'.

Beginning as early as 1949 leading musicians such as Miles Davis and Gil Evans wanted to bring the rhythms and harmonies of bebop to a wider audience and build a better balance between the soloist and the group. That year Davis's nonet made a set of records, not released until 1957, named Birth of the Cool. In 1952 the Gerry Mulligan /Chet Baker quartet created its own intricate style.

The horns played counterpoint. The drums and bass played melodic lines as well as rhythm and the rhythm itself shifted effortlessly from Dixieland two-step to 4/4 bebop-style polyrhythms and back again" (Ward and Burns 2000: 375). 
The Modern Jazz Quartet — originally part of the Gillespie Big Band — played a carefully balanced equilibrium between written and improvised music, and incorporated classical themes. The Dave Brubeck Quartet, an original group, incorporating unusual time signatures such as 5/4 or 9/8.

But the musician who defined the new ordered style was Miles Davis and the various musicians who played with him, particularly John Coltrane. His was the first jazz to be described as 'cool'. Some of the most original music used simple basic scales or 'modes'. The album Kind of Blue became a best selling album and characterized this era of repetitive focussing.

Although rock and roll was popular by 1960, the record stores still sold many great jazz records by such musicians as Davis, Coltrane, Monk, Brubeck, and others. In the mid-Fifties jazz festivals such as the Newport Jazz Festival were inviting musicians from all genres-Dixieland to cool - to play, and jazz of all kinds was getting an exposure.

The integration of bebop into more traditional arrangements, along with improvisations, characterized this post-bebop era, a recognizable form repeated in various ways by most jazz musicians.

\section{Avant-garde, free and extreme jazz 1960-1970: Complex focussing}

The Sixties saw major changes in the social structure of American society. They were characterised by the expansion of more rights for black Americans a process that had started during the War with Gunnar Myrdal's classic challenge to the idea of 'separate but equal' education (1944). The civil rights struggle, led by people such as Martin Luther King, resulted in a restructuring of race relations. For jazz, beginning in 1960, the Civil Rights' Movements increased the centrality of black and, indirectly, white musicians but was not accompanied by an equivalent increase in differentiation, so jazz moved back into complexity out of which emerged free or extreme jazz. Differentiation remained constant because the instruments were the same and there were still relatively few players with the skills to play the new emergent jazz.

The new form originated in the late Fifties when several musicians such as Cecil Taylor, John Coltrane and Ornette Coleman sought to extend jazz to the next level. Essentially, this meant going beyond the chords of the melody and into complex polyrhythms. In the hands of musicians of stature it became an important force in jazz during the Sixties.

There was major debate about this music in the mid-Sixties, but aspects of it were picked up by various jazz musicians, and people like Miles Davis, Sonny Rollins and Jackie McLean made records incorporating this style.

\section{Many voices and few listening 1968-1980: Chaotic focussing}

During the rapid changes of the Sixties, society could not adjust quickly by differentiating to cope with the increased centrality and all the new information flooding American society. As a result, both the greater society and the system of jazz music descended into chaos. A major factor was the huge demographic shift caused by the leading edge of the post-war baby boom reaching adolescence and challenging the values of their parents (Szatmary, 1995). Other outside events impacted jazz. In particular, continuing progress in black rights made the relationships among musicians and the kind of music that they would play very complicated. By the late Sixties, jazz had many, sometimes confusing, voices. 
At the same time, with rock and roll king, jazz was not widely played, especially by young musicians, so differentiation was reduced as centrality increased. The result was a diminished $\mathrm{d} / \mathrm{c}$ ratio and chaotic focussing. With free jazz almost inaccessible and rock and roll at its highest popularity, jazz almost disappeared in the Seventies. It was still played, however, much of it on university campuses. Jobs for jazz musicians were minimal, however, and they looked for other musical careers or left the business.

The jazz that was played was either a derivative of free jazz or a combination of jazz and rock and roll termed fusion. Even Miles Davis experimented with fusion with the album Bitches Brew, which marked his departure from pure jazz. There were many small schools of jazz or near-jazz and the argument about which was or was not jazz was almost more interesting than the music.

\section{The resurgence of a great art 1980 - to the Present: Repetitive Order}

The 1980s saw a resurgence of jazz. Centrality was essentially constant as the music now permeated the whole musical world. The common objective was to play jazz well, whether it was New Orleans or free jazz. An increase in differentiation came as new musicians appeared and the reissue of classic jazz records introduced jazz to many young musicians. The result was repetitively ordered focussing for all jazz in all its many styles, albeit with a much smaller audience than it had during earlier classical periods of order. Jazz had become, like European classical music, its own genre.

The return of Dexter Gordon, a bebop master, from Europe in 1976 marks the resurgence of jazz. His playing revealed the power and aesthetic scale of this art (Ward and Burns, 2000: 420). This rebirth meant that one could hear music in all the idioms. New bands, such as the Lincoln Centre Band, were organized but they played the jazz of all periods.

Records of every description are being produced by young new musicians. The music is ordered, a rebirth of old orders. It is all-inclusive and includes music from all ages of jazz... and, above all, it swings.

\section{Conclusions}

We recognize that there are many sub-arguments in the history of jazz that are not covered in this brief review based on Ken Burns' work. His history is by no means all inclusive but we believe it covers the major phases of the jazz evolution and the emergence of new structures, at least until the end of the1980s. As such, it serves to illustrate the power of $\mathrm{d} / \mathrm{c}$ and social focussing theory to explain social change.

We also see our work as advancing the field of socio-cybernetics. Geyer's classic paper (1994) describes in detail the earlier forms of cybernetics. Beginning in the 1940s in the field of engineering, first-order cybernetics developed as a way of analysing the mechanics of steeringkeeping a system in its current ordered state. Using negative feedback, observations of output guided new inputs to eliminate deviation. This concept was extended from control mechanisms into fields such as artificial intelligence (Geyer, 1994:15). The overall goal was homeostasisminimizing changes in output. For sociology, this led to structural functionalism, as a way of explaining how social systems maintained order and prevented change (Geyer, 1994:5).

in addition to its inherently conservative nature, used to justify existing social systems with all its inequality, Geyer points out that these early cybernetic ideas also introduced the concepts of systems theory, which we use in this paper, that is, the idea of system boundaries, of suprasystems and subsystems, along with the concept of circular causation, where a change in input changes output, which in turn can be fed back as input to then change output. This was a significant step 
away from the 19th century assumption of linear causation, where every result can be determined by discovering its cause. Crucial for our approach here was this demonstration by first-order cybernetics that we can apply theories from the physical sciences to the social sciences, and even simulate and experiment with virtual systems in order to understand and change society. (Geyer, 1994:6-9).

Second-order cybernetics put more emphasis on changing the output, rather than maintaining it, that is, morphogenesis, most obviously, through positive or deviation amplifying processes. Secondorder cybernetics is also seems more applicable to social systems where, instead of the automated, mechanical processes of suppressing deviation emphasised in first-order cybernetics, human beings are much more likely to consciously observe results, and then use calculated decisions to bring about different results (Geyer, 1994:9ff). This second period of cybernetic theory development, essentially the final three decades of the 20th century, generated several terms to describe how second-order cybernetics works, especially in social systems. Such terms as self-referencing and autopoiesis, emphasizing, respectively, the human ability to be conscious of what is going on now, and secondly, actively producing and reproducing for the future. It is consciousness which most clearly distinguishes living, biological systems from mechanical ones found elsewhere in nature (Geyer, 1994:9ff).

Geyer, throughout his paper, refers to emergence, complexity and self-organisation, without really distinguishing it from other terms of second-order cybernetics. We have emphasized here that emergence of new systems during the stage of complexity at the edge of chaos, is a significantly new phenomenon not directly derivable from the earlier two cybernetic ideas. We believe system emergence during the complex stage may represent a third-order of cybernetics, not yet fully understood. Whereas the effects of first-order cybernetics are predictable and fixed outputs, and the product of second-order cybernetics is changed results, both refer to a given system. Third-order cybernetics is about the appearance of a brand new systems, which frequently have quite surprising new structures and new goals.

To repeat, emergence is not in itself a new idea, but we think we have shown how a transitions into the stage of complexity is the way to generate, in the case of jazz, entirely new structures and new styles. We have shown that the $\mathrm{d} / \mathrm{c}$ ratio can explain why systems move from stage to stage, in particular, how it was during periods of complexity we saw emerge the original New Orleans jazz, the big band era, bebop and the other styles. we have described in this paper. We illustrate how it is possible to move systems from one stage to the other, and, in particular, how completely unpredictable systems emerge during times of complexity.

We believe further study would find many subsystems of the jazz social system went through their own cycles of chaos, complexity and new repetitive order. Thus, the music that came from the Midwest to New Orleans in the 19th century, or the development of West Coast jazz could be studied, and, we would suggest each subsystem would show similar cycles of social focussing. Indeed, it is likely that musical groups from small trios to big bands went through similar cycles from their formation until they were disbanded. The world of jazz is fractal, patterns of the same shape at all system levels (Mandelbrot, 1983; 1977). 


\section{References}

Ashby, W. R. (1966 (1956)). An Introduction to Cybernetics. New York: John Wiley.

Burns, K. (2001). Jazz: A Film by Ken Burns. United States: PBS.

Corning, P. A. (2002). The re-emergence of "emergence": A venerable concept in search of a theory. Complexity 7 (6), 18-30.

Flynn, D. \& Hay, J. M. (2012). Making Social Change. Sarnia, Ontario, Canada: Grafiks Publishing.

Flynn, D. \& Hay, J. M. (2013). Changing social focussing in indigenous social movements. Journal of Sociocybernetics, $1 / 2$.

Geyer, Felix. (1994). The challenge of social cybernetics. 13th World Congress of Sociology: Symposium VI. Subsequently published in Kybernetes 24(4):6-32, 1995.

Hay, J. M. \& Flynn, D. (2011). Changing the state of abstract discrete systems. Complex Systems, 19(3). Hay J. M. and Flynn, D. (2015). The effect of network structure on individual behaviour. Complex Systems, 23(4).

Holland, J. H. (1998). Emergence from Chaos to Order. Oxford University Press.

Kauffman, S. (1995). At Home in the Universe. Oxford University Press.

Mandelbrot, B. B. (1983 (1977)). The Fractal Geometry of Nature. New York: Freeman.

Myers, M. (2013). Why Jazz Happened. Berkeley, CA: University of California Press.

Myrdal, G. (1944). An American Dilemma: The Negro Problem and Modern Democracy. New York: Harper \& Bros.

Page, S. E. (2009). Understanding Complexity. The Teaching Company.

Szatmary, D. P.. (2014). Rocking in Time: A Social History of Rock and Roll (8th ed.). Pearson.

Verala, Francisco, Evan Thompson, and Eleanor Rosch. (1993). The Embodied Mind-Cognitive Science and Human Experience (3rd ed.). Cambridge, MA: MIT Press.

Ward, C. W. \& Burns, K. (200o). Jazz: A History of America's Music. New York: Knopf,

Wasserman, S. \& Faust, K. (1994). Social Network Analysis: Methods and Applications. Cambridge University Press.

Watts, J. D. (1999). Small Worlds: The Dynamics of Networks Between Order and Randomness. Princeton NJ: Princeton University Press.

Wolfram, S. (2002). A New Kind of Science. Champaign, Ill: Wolfram Media.

Young, F. W. and Young, R. C. (1973). Comparative Studies of Community Growth. Charleston, WV: West Virginia University Press. 